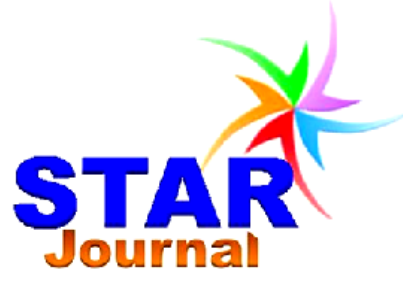

ISSN: 2226-7522(Print) and 2305-3327 (Online) Science, Technology and Arts Research Journal

April-June 2012, 1(2):31-42

www.starjournal.org

Copyright $\odot 2012$ STAR. All Rights Reserved

Original Research

\title{
Determinants of HIV Testing Among Tuberculosis Patients on DOTS in East Wollega Zone, Ethiopia
}

\author{
Gebi $A^{1 *}$ and Alemayehu $\mathbf{W}^{2}$ \\ ${ }^{1}$ Faculty of Health Sciences, Post Box No: 395, Wollega University, Nekemte, Ethiopia \\ ${ }^{2}$ School of Public Health, Addis Ababa University, Addis Ababa, Ethiopia
}

\begin{tabular}{|c|c|}
\hline Abstract & $\begin{array}{l}\text { Article Information } \\
\text { Article History }\end{array}$ \\
\hline $\begin{array}{l}\text { The main aim of the study was to assess determinants of HIV testing among } \\
\text { Tuberculosis patients on DOTS in East Wollega zone, Ethiopia. Institution } \\
\text { based case control study was conducted from January - March } 2011 \text {. Cases } \\
\text { were tuberculosis patients who have not accepted HIV testing while the } \\
\text { controls were those who have accepted HIV testing. A sample of } 270 \text { ( } 90 \\
\text { cases and } 180 \text { controls) tuberculosis patients, with a ratio of two controls to } \\
\text { one case, was used. Simple random sampling technique was used to recruit } \\
\text { study subjects. Tuberculosis patients who was tested for HIV showed, } \\
23(12.8 \%) \text { of them were HIV positive and } 157(87.2 \%) \text { of them were HIV } \\
\text { negative. The proportion of HIV infected individual was } 10(13.2 \%) \text { among } \\
\text { males and } 13(12.5 \%) \text { among females. Among } 23 \text { patients, } 19(16.4 \%) \text { TB } \\
\text { patients from urban and } 4(6.2 \%) \text { patients were from rural area. Tuberculosis } \\
\text { patients having low knowledge about HIV and were more likely to reject HIV } \\
\text { testing AOR } 3.697 \text { (CI } 2.135,6.402) \text { compared to those who are } \\
\text { knowledgeable about HIV. Higher level of stigmatized attitude toward HIV and } \\
\text { being from urban were also associated with rejecting HIV testing AOR } \\
3.421(\mathrm{Cl} 1.870,6.257) \text { and AOR } 5.692(\mathrm{Cl} 1.930,16.783) \text { respectively. Efforts } \\
\text { to promote HIV testing utilization require effective strategies to reduce } \\
\text { stigmatizing beliefs towards HIV and PLWHA among TB patients. Health } \\
\text { information dissemination regarding HIV testing and risky sexual behavior } \\
\text { reduction should have to be targeted most at risk population like tuberculosis } \\
\text { patients. }\end{array}$ & $\begin{array}{l}\text { Tuberculosis } \\
\text { HIV } \\
\text { Urban } \\
\text { Rural } \\
\text { Perception } \\
{ }^{*} \text { Corresponding Author: } \\
\text { Gebi A } \\
\text { E-mail: } \\
\text { gebi.agero@yahoo.com }\end{array}$ \\
\hline
\end{tabular}

\section{INTRODUCTION}

Tuberculosis (TB) is the most common cause of death among people living with HIVIAIDS (PLWHA). The World Health Organization (WHO) recommends that in countries where HIV prevalence is at least $1 \%$ among adults and $5 \%$ among TB patients, all TB patients should be offered HIV testing and all PLWHA should be screened for TB and to increase uptake of HIV testing, WHO also recommends provider-initiated HIV testing and counseling (PITC) (WHO, 2004). HIV related Tuberculosis remains serious challenge for health sector response to HIV. All countries with a generalized HIV epidemic state should aim to ensure that HIV testing is actively promoted and offered to all TB patients. The data available from these initiatives can form the basis of a reliable surveillance system that achieves high coverage $(>80 \%)$ of testing among TB patients(WHO, 2004). Thus, the high rate of HIV infection and poorly functioning tuberculosis control programs in many parts of Africa are likely to contribute to the emergence of extreme drug resistant (XDR) tuberculosis, which could destabilize the control of tuberculosis in these 
areas (Dheda Shean et al., 2010). Sub-Saharan Africa continues to account for the majority of people living with HIV and TB in the world. In 2007 , about $79 \%$ of the estimated total people living with HIV and TB were in this region posing other burden like risk of drug resistant forms of TB due to difficulty and delays in diagnosis, increased mortality and greatly reduced survival time(WHO UNAIDS Unicef Progress Report, 2009).

Tuberculosis (TB) is the initial clinical manifestation of human immunodeficiency virus (HIV) disease for many people in sub-Saharan Africa, and a very high proportion of TB patients in this region are co-infected with HIV. HIV counseling and testing of TB patients is therefore an important method for identifying HIV-infected individuals, all of whom require HIV care and many of whom are indicated for antiretroviral therapy (Zachariah Spielmann et al., 2003). A test done among TB suspects revealed a $42 \%$ HIV seropositive of these, $37 \%$ received a nonTB diagnosis. Patients who received a non-TB diagnosis were significantly more likely to be HIVseropositive than those who were diagnosed with TB $(49 \%$ vs $39 \%$; odds ratio or $1.6,95 \%$ confidence interval (1.1-2.2, $P=0.02)$ (Srikantiah Lin et al., 2007). WHO estimates that in Ethiopia $40 \%$ of TB patients tested for HIV are HIV positive, (WHO UNAIDS Unicef Progress Report 2009). While a study done in Arbaminch demonstrated that the prevalence of HIV among tuberculosis patients was high among individuals from urban areas and TB-HIV co-infection was high among women's (32.3\% versus $10.8 \%$ among men) and there is no significant difference between urban and rural in TB-HIV co-infection, but study done in Cameroon demonstrated a 68.5\% HIV seropositive prevalence among TB patients (Jerene Endale et al., 2007; Njozing Migue et al., 2010) Factors like individuals self perceived risk of HIV infection were associated with initial willingness but are not associated with actually accepting the result, concerns about confidentiality, convenient timing of the service, level of spoken English and place of the testing site have been described as determinants of acceptability of HIV testing services (Pignatelli Simpore et al., 2006; Angotti Bula et al., 2009; Rodger Story et al., 2010; Mpairwe, Muhangi et al., 2005; Knut and Seter, 2004).

Operational factors like not understanding the process during group education session/pre test counseling, disagreement of the partner, wanting the partner to be tasted before hand, having salesman partner and the perception that the community would have negative attitude are explained as determinant factor for participation in HIV counseling and tasting. Distance to HIV testing site (presence of onsite HIV tasting) was associated with client's uptake of HIV testing among TB patients (Pignatelli Simpore et al., 2006; Sarker, Sanou et al., 2007; Kanara Cain et al., 2009). To realize the right to health, states need to identify groups at risk of HIV in order to develop effective HIV prevention and control programs(Kouyoumdjian Seisay et al., 2010). VCT services may provide a means for States to fulfill the right to health as a way to prevent HIV and as the gateway for people with HIV to access health care. However, States must ensure that VCT is accessible and acceptable to the whole population at risk of HIV (Kanara Cain et al., 2009; Kouyoumdjian Seisay et al., 2010). Testing practices are highly dependent on the local culture of the clinics and the individual practices of healthcare workers (Rodger Story et al., 2010).

\section{MATERIALS AND METHODS}

\section{Study Area and Period}

The study was conducted in East Wollega zone, Oromia regional state, Western Ethiopia. East Wollega Zone is one of the zones of Oromia Regional state with a population of $1,230,402$ among which 614,761 are males and 615,641 are females. Majority of the population live in rural areas $86 \%(1,061,120)$ (FDRE, 2008). Nekemte is the capital city of the zone which is located $331 \mathrm{~km}$ west of Addis Ababa with a population of 76,817 (male 39,167 and female 37,650). The study was conducted from January to March, 2011.

\section{Study Design}

Institution based unmatched case control study design was used to assess determinants of HIV testing among tuberculosis patients on DOTS. Determinants were assessed among TB patients those who had taken HIV testing (controls) and those refused to accept HIV testing (cases).

\section{Inclusion and Exclusion Criteria}

TB patients aged less than 18 years and those for whom HIV had been diagnosed before TB were not included in the study. Whereas newly diagnosed, previously registered and those under treatment including all forms of TB in Nekemte Hospital and selected health centers during the study period were selected for the study.

\section{Sample Size}

The sample size was determined by using a formula for estimating two population proportions, $80 \%$ power and $5 \%$ type I error to approximate an acceptable population parameter and a $10 \%$ 
non response rate was used. The formula used for calculating the required sample size was computed by using, ever heard about HIV testing as exposure variable and taking 1:2 ratio (for one case two controls), since it yields maximum sample size (Ayenew Leykun et al., 2010).

Where the proportion of exposure among cases (27.2) and the proportion of exposure among controls (11.7). A significance level of alpha (1.96 for a two-sided test at the 0.05 alpha level) and $Z 1-\beta / 2$ value of standard normal distribution corresponding to the desired level of power $(0.84$
Sci. Technol. Arts Res. J., April-June 2012, 1(2):31-42

for a power of $80 \%$ ). Total sample size required for the study was 270 tuberculosis patients on DOTS (90 cases and 180 controls).

\section{Sampling Procedure}

List of all tuberculosis patients on DOTS was obtained from six health centers selected randomly from Nekemte hospital registration book. Before generating random number subjects were screened for inclusion and exclusion criteria, then simple random sampling technique was employed to select individual study participant.

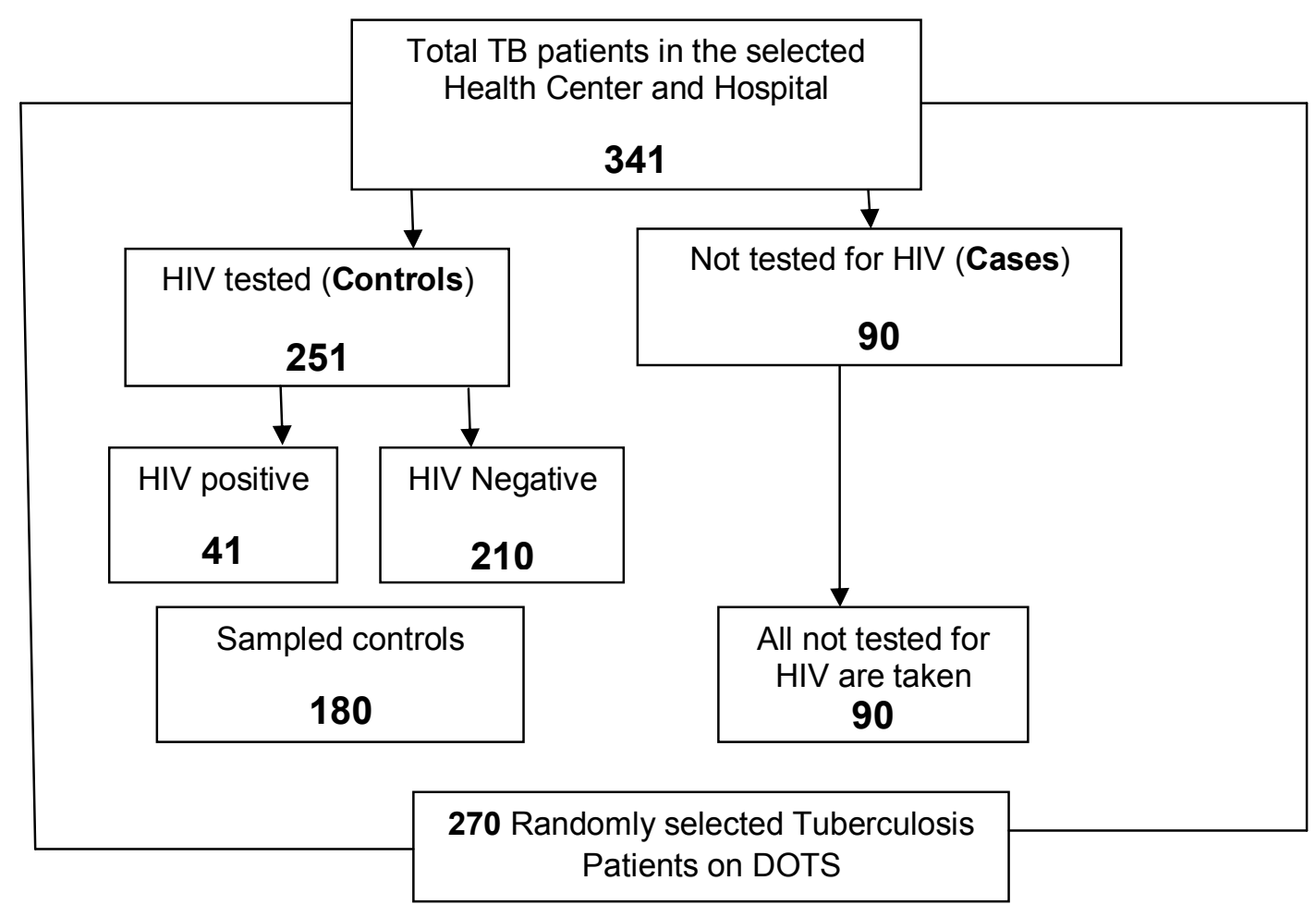

Figure 1: Sampling procedure for assessment of determinants of HIV testing among tuberculosis patients on DOTS in East Wollega zone, Ethiopia 2011.

\section{Data Collection}

Questionnaires that were prepared in English language were translated to Afan Oromo language for data collection. The questionnaires contain socio-demographic characteristics, marital status, educational level, type of TB, place of residence, income, distance from health service, HIV related knowledge and intention to use VCT services. Pre-test of the questionnaire for clarity and consistency of the questions was conducted on 24 tuberculosis patients from Jimma Arjo health center that was not included in selected health centers for final data collection (from similar woredas in East Wollega zone) one week prior to actual data collection. Finally, necessary amendment was made based on the feedback.
Seven data collectors were recruited, three females and four males. Two days training was given to them focusing on the objective of the study and value of collecting the actual data. Data was collected by nurses trained in data collection; they were selected from their respective TB units. Structured questionnaire were used for data collection by interviewing TB patients after they have received their treatment.

\section{Data Processing and Analysis}

Quantitative data was entered and cleaned using Epi Info soft ware, and after clearance data was exported to SPSS version 17 for analysis. Thirteen questionnaires were used to assess knowledge regarding tuberculosis and HIV, the 
questionnaires were then given a mark of one, if the respondent answered the question correctly and given zero, if the answer was wrong, finally a summary score of all the questions were calculated. The mean of correct answer were used as a cutoff point, respondent who have answered greater than the mean were categorized as knowledgeable and those whose scores were less than the mean were categorized as non-knowledgeable. Similarly seven question were used to assess perceived stigma and discrimination related to HIV, those respondents whose scores were less the mean were categorized as having high perceive stigma and discrimination and those whose scores were greater than the mean were categorized as having low perceived stigma and discrimination. Binary logistic regression was used for both bivariate and multivariate analysis. A final model was developed using stepwise forward logistic to see the joint effect of socio-demographic and knowledge, attitude and perceived stigma towards HIV testing. Statistical significance was taken at $p<0.05$.

\section{Data Quality Control}

Pre-test was conducted out of study subjects to detect any problem in the questionnaire and data collection method. All filled questionnaires were checked daily for completeness, accuracy, clarity and consistency by the supervisor and the principal investigator and necessary corrections and changes was made. Completeness and consistency of variables during data entry was checked using frequency distributions. Appropriate statistics was used for describing the variables and their associations.

\section{Ethical Consideration}

Permission was taken from Ethical review committee of the SPH of Addis Ababa University, East Wollega zonal health office and from study units. At individual level after explaining the purpose of the study verbal and written consent was obtained from all participants prior to their participation in the study. HIV testing that was done prior to data collection by the respective health centers was used and HIV test result were retrieved from TB patient log book during data collection in selected health center in TB clinic, the study subjects were informed that their name or special ID will not be included in the report than HIV status that doesn't contain any information related to individual study subject.

\section{RESULTS}

\section{Socio-demographic Characteristics}

The socio-demographic characteristics of respondents are shown in Table 1. Two hundred seventy tuberculosis patients $(100 \%$ both HIV tested and not tested for HIV) responded to the questionnaire completely. Of these $111(41.1 \%)$ of them were males and $159(59.9 \%)$ were females. The mean age of respondents was $33.52 \pm 10.29$ for cases and $31.71 \pm 11.94$ years for controls (Table 1).

\section{Knowledge, Attitude and Perceived Stigma towards TB/HIV}

Thirteen questions were asked to assess knowledge and seven questions were also used to assess perceived stigmatized attitude towards TB/HIV, then for respondents who answered the question correctly a mark of one was given and zero was given for wrong answers. Accordingly mean value of correct answer was calculated and respondents scoring less than mean value were categorized as having low knowledge and high stigmatizing attitude. Regarding type of TB, stage of treatment and previous history of TB, more than one third $(35.6 \%)$ of the respondents are smear positive pulmonary TB while 114(42.2\%) and $60(22.2 \%)$ are smear negative and extra pulmonary TB respectively. One hundred twenty four $(45.9 \%)$ of them are on intensive phase while $146(54.1 \%)$ of them are on continuous phase of treatment, from these $11(4.1 \%)$ of them had previous history of TB (Table 2).

\section{HIV Testing}

Seventy six (84.4\%) of cases and $170(94.4 \%)$ controls have ever heard about HIV testing (VCT, PIHCT). The main sources of information were mass media 57(68.7\%), 135(69.6\%), news paper $10(12.1 \%), \quad 30(15.5 \%)$ and family/relatives $8(9.6 \%), 17(8.8 \%)$ for cases and controls respectively. The respondents were also asked if they knew where to get HIV counselling and testing (HCT), 83(92.2\%) of cases and $168(93.3 \%)$ controls reported that they know where to get HCT. However less than half of cases $46.7 \%$ agreed that HCT is important compared to $168(93.3 \%)$ of controls arguing that HCT is important. In addition to this more than half $51(56.7 \%)$ of case and $10(5.6 \%)$ controls claim that there is no benefit of being tested for HIV (Table 3).

One hundred seventy six $(65.2 \%)$ of the respondents' had sex in the past 12 months, in which $140(79.5 \%), 29(16.5 \%)$ and $7(4 \%)$ of them had sex with regular partner/wife, non regular partner and commercial sex workers (CSW) 
Table 1: Socio-demographic characteristics of Tuberculosis patients on DOTS in East Wollega Zone, Ethiopia, January to February 2011.

\begin{tabular}{|c|c|c|c|}
\hline Variables & Cases(n=90) & Controls $(n=180)$ & Total $(n=270)$ \\
\hline \multicolumn{4}{|c|}{ - } \\
\hline Male & $35(38.9 \%)$ & $76(42.2 \%)$ & $111(41.1 \%)$ \\
\hline Female & $55(61.1 \%)$ & $104(57.8 \%)$ & $159(59.9 \%)$ \\
\hline \multicolumn{4}{|l|}{ Age in years } \\
\hline$<25$ & $19(21.1 \%)$ & $64(35.6 \%)$ & $83(30.7 \%)$ \\
\hline $25-34$ & $32(35.6 \%)$ & $51(28.3 \%)$ & $83(30.7 \%)$ \\
\hline $35-44$ & $23(25.6 \%)$ & $36(20 \%)$ & $59(21.9 \%)$ \\
\hline$>=45$ & $16(17.8 \%)$ & $29(16.1 \%)$ & $45(16.7 \%)$ \\
\hline \multicolumn{4}{|l|}{ Place of residence } \\
\hline Urban & $71(78.9 \%)$ & $116(64.4 \%)$ & $187(69.3 \%)$ \\
\hline Rural & $19(21.1 \%)$ & $64(35.6 \%)$ & $83(30.7 \%)$ \\
\hline \multicolumn{4}{|l|}{ Marital status } \\
\hline Single/Never married & $40(44.4 \%)$ & $73(40.6 \%)$ & $113(41.9 \%)$ \\
\hline Married & $40(44.4 \%)$ & $86(47.8 \%)$ & $126(46.7 \%)$ \\
\hline Divorced & $4(4.4 \%)$ & $5(2.8 \%)$ & $9(3.3 \%)$ \\
\hline Widowed & $6(6.7 \%)$ & $16(8.9 \%)$ & $22(8.1 \%)$ \\
\hline \multicolumn{4}{|l|}{ Ethnicity } \\
\hline Oromo & $63(70 \%)$ & $120(66.7 \%)$ & $183(67.8 \%)$ \\
\hline Amhara & $17(18.9 \%)$ & $53(29.4 \%)$ & $70(25.9 \%)$ \\
\hline Tigre & $3(3.3 \%)$ & $2(1.1 \%)$ & $5(1.9 \%)$ \\
\hline Others & $7(7.7 \%)$ & $5(2.8 \%)$ & $12(4.4 \%)$ \\
\hline \multicolumn{4}{|l|}{ Religion } \\
\hline Orthodox & $27(30 \%)$ & $69(38.3 \%)$ & $\begin{array}{l}96(35.6 \%) \\
123(456 \%)\end{array}$ \\
\hline Muslim & $55(61.1 \%)$ & $68(37.8 \%)$ & $123(45.6 \%)$ \\
\hline Protestant & $5(5.6 \%)$ & $38(21.1 \%)$ & 43(15.9\%) \\
\hline Catholic & $3(3.3 \%)$ & $5(2.8 \%)$ & \\
\hline \multicolumn{4}{|l|}{ Highest level of education } \\
\hline Unable to read and write & $42(46.7 \%)$ & $55(30.6 \%)$ & $9 /(35.9 \%)$ \\
\hline Primary & $7(7.8 \%)$ & $36(20 \%)$ & $43(15.9 \%)$ \\
\hline Secondary & $18(20 \%)$ & $40(22.2 \%)$ & $58(21.5 \%)$ \\
\hline High school and above & $23(25.6 \%)$ & $49(27.2 \%)$ & \\
\hline \multicolumn{4}{|l|}{ Employment status } \\
\hline Employed & $16(17.8 \%)$ & $22(12.2 \%)$ & $\begin{array}{l}38(14.1 \%) \\
232(85.9 \%)\end{array}$ \\
\hline Unemployed & $74(82.2 \%)$ & $158(87.8 \%)$ & \\
\hline \multicolumn{4}{|l|}{ Distance from health institution } \\
\hline$<=10 \mathrm{~km}$ & $84(93.3 \%)$ & $161(89.4 \%)$ & $245(90.7 \%)$ \\
\hline$>10 \mathrm{~km}$ & $6(6.7 \%)$ & $19(10.6 \%)$ & $25(9.3 \%)$ \\
\hline \multicolumn{4}{|l|}{ Average monthly income(ETB) } \\
\hline$<500$ & $47(52.2 \%)$ & $104(57.8 \%)$ & $151(57.9 \%)$ \\
\hline $500-1000$ & $12(13.3 \%)$ & $18(10 \%)$ & $30(11.1 \%)$ \\
\hline$>1000$ & $7(7.8 \%)$ & $10(5.6 \%)$ & $17(6.3 \%)$ \\
\hline No income & $24(26.7)$ & $48(26.7)$ & $72(26.7 \%)$ \\
\hline
\end{tabular}

respectively. Less than one fourth $39(22.15 \%)$ of the respondents have used condom, and the frequency of condom use was reported as $21(11.9 \%), 13(7.4 \%), 18(10.2 \%)$ and $127(72.2)$ used every time, almost every time, sometimes and never respectively (Table 3).

\section{Factors Associated with Acceptance of HIV Testing}

A final model using stepwise forward method using $P<0.3$ was used to describe the joint effect of socio-demographic variables and knowledge and behavior variables related to HIV testing that have shown significant association on crude/multivariate analysis was used and a variable having $P<0.05$ was used for significant association. Patients having positive perceived benefit of HIV testing and accepting HCT if offered house to house were less likely to reject HIV testing both on crude and multi-variate analysis (Table 4). 
Table 2: Percentage distribution of knowledge, attitude and perceived stigma towards TB/HIV among Tuberculosis patients on DOTS in East Wollega Zone, Ethiopia, January to February 2011.

\begin{tabular}{|c|c|c|c|}
\hline $\begin{array}{c}\text { Variables } \\
\end{array}$ & Cases $(n=90)$ & Controls $(n=180)$ & Total $(n=270)$ \\
\hline \multicolumn{4}{|c|}{ Heard about TB(ever/before sickness) } \\
\hline Yes & $87(96.7 \%)$ & $160(88.9 \%)$ & $247(91.5 \%)$ \\
\hline No & $3(3.3 \%)$ & $20(11.1 \%)$ & $23(8.5 \%)$ \\
\hline \multicolumn{4}{|l|}{ Source of Information } \\
\hline Radio/Television & $76(87.36 \%)$ & $112(70 \%)$ & 188(76.11\%) \\
\hline News paper/Magazines & $4(4.6 \%)$ & $28(17.5 \%)$ & $32(12.95 \%)$ \\
\hline Parent/relatives & $5(5.75 \%)$ & $11(6.87 \%)$ & $16(6.48 \%)$ \\
\hline Health institution & $5(5.755)$ & $28(17.5 \%)$ & $33(13.36 \%)$ \\
\hline Others & 0 & $1(0.625 \%)$ & $1(0.4 \%)$ \\
\hline \multicolumn{4}{|l|}{ Afraid of being infected with TB } \\
\hline Yes & $4(4.4 \%)$ & $30(16.7 \%)$ & $34(12.6 \%)$ \\
\hline No & $86(95.6 \%)$ & $150(83.3 \%)$ & $236(87.4 \%)$ \\
\hline \multicolumn{4}{|l|}{ Who is at risk of getting TB } \\
\hline The poor & $14(15.5 \%)$ & $34(18.9 \%)$ & $48(17.8 \%)$ \\
\hline Rural people & $5(5.6 \%)$ & $12(6.7 \%)$ & $17(6.35)$ \\
\hline Those who live with TB & $64(71.1 \%)$ & $83(46.1 \%)$ & $147(54.4 \%)$ \\
\hline Smokers/Alcolics & $7(7.8 \%)$ & $27(15 \%)$ & $34(12.6 \%)$ \\
\hline Others & 0 & $24(13.3 \%)$ & $24(8.8 \%)$ \\
\hline \multicolumn{4}{|l|}{ As a TB patient reveal it to others } \\
\hline Yes & $44(48.9 \%)$ & $122(67.8 \%)$ & $166(61.5 \%)$ \\
\hline No & $46(51.1 \%)$ & $58(32.2 \%)$ & $104(38.5 \%)$ \\
\hline \multicolumn{4}{|l|}{ Type of TB } \\
\hline Smear positive PTB & $40(44.4 \%)$ & $56(31.1 \%)$ & $96(35.6 \%)$ \\
\hline Smear negative PTB & $44(48.9 \%)$ & $70(38.9 \%)$ & $114(42.2 \%)$ \\
\hline Extra pulmonary TB & $6(6.7 \%)$ & $54(30 \%)$ & $60(22.2 \%)$ \\
\hline \multicolumn{4}{|l|}{ Heard about HIVIAIDS } \\
\hline Yes & $90(100 \%)$ & $171(95 \%)$ & $261(96.7 \%)$ \\
\hline No & 0 & $9(5 \%)$ & $9(3.3 \%)$ \\
\hline \multicolumn{4}{|c|}{ Healthy looking person can be infected with HIV } \\
\hline Yes & $74(82.2 \%)$ & $124(68.9 \%)$ & 198(73.3\%) \\
\hline No & $16(17.8 \%)$ & $56(31.1 \%)$ & $72(26.7 \%)$ \\
\hline \multicolumn{4}{|c|}{ There is relationship between TB and HIV } \\
\hline Yes & $24(26.7 \%)$ & $95(52.8 \%)$ & $119(44.1 \%)$ \\
\hline No & $66(73.3 \%)$ & $85(47.2 \%)$ & $151(55.9 \%)$ \\
\hline \multicolumn{4}{|l|}{ TB increase after era of HIV } \\
\hline Yes & $22(24.4 \%)$ & $99(55 \%)$ & $121(44.8 \%)$ \\
\hline No & $68(75.6 \%)$ & $81(45 \%)$ & $149(55.2 \%)$ \\
\hline \multicolumn{4}{|c|}{ Control of HIVIAIDS prevent spread of TB } \\
\hline Yes & $21(23.3 \%)$ & $91(50.6 \%)$ & $112(41.5 \%)$ \\
\hline No & $69(76.7 \%)$ & $89(49.4 \%)$ & $158(58.5 \%)$ \\
\hline \multicolumn{4}{|l|}{ HIVIAIDS can be cured } \\
\hline Yes & $4(4.4 \%)$ & $13(7.2 \%)$ & $17(6.3 \%)$ \\
\hline No & $86(95.6 \%)$ & $167(92.8 \%)$ & $153(93.7 \%)$ \\
\hline \multicolumn{4}{|c|}{ Person can get HIV from mosquito bite } \\
\hline Yes & $21(23.3 \%)$ & $35(19.4 \%)$ & $56(20.7 \%)$ \\
\hline No & $69(76.7 \%)$ & $145(80.6 \%)$ & $214(79.3 \%)$ \\
\hline \multicolumn{4}{|c|}{$\begin{array}{l}\text { One gets HIV by sharing meal with someone } \\
\text { infected with HIV }\end{array}$} \\
\hline Yes & $5(5.6 \%)$ & $28(15.6 \%)$ & $33(12.2 \%)$ \\
\hline No & $85(94.4 \%)$ & $152(84.4 \%)$ & $237(87.8 \%)$ \\
\hline \multicolumn{4}{|c|}{$\begin{array}{l}\text { One gets HIV by shaking Hands and clothes } \\
\text { living with HIVIAIDS }\end{array}$} \\
\hline Yes & $5(5.6 \%)$ & $30(16.7 \%)$ & $35(13 \%)$ \\
\hline No & $85(94.4 \%)$ & $150(83.3 \%)$ & $235(87 \%)$ \\
\hline
\end{tabular}




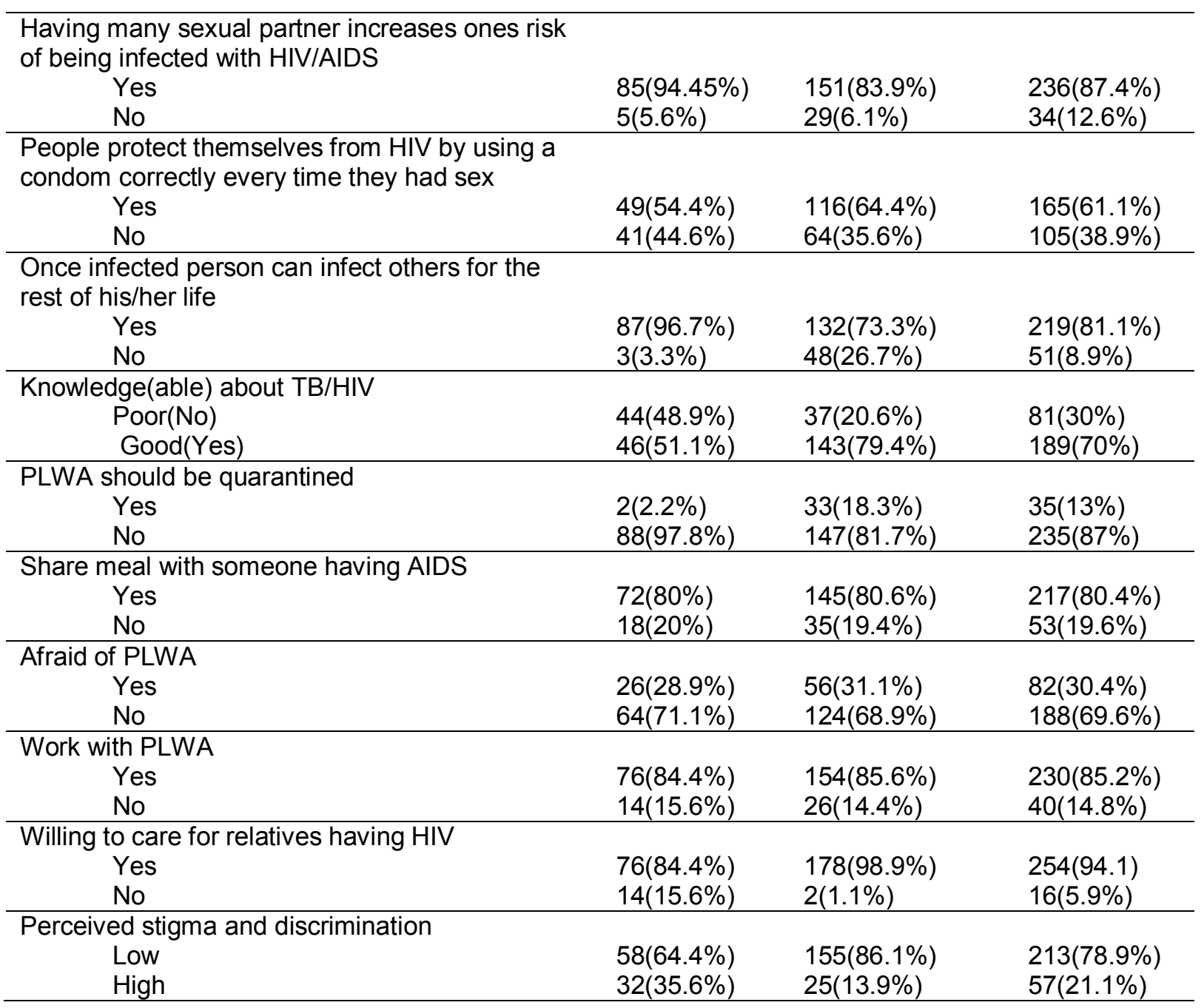

\section{DISCUSSION}

A patient registration document review of 73.3\% HIV test acceptance among TB patients in the source population is low compared to other African countries like Malawi and Cameroon (Zachariah Teck et al., 2006; Njozing Migue et al., 2010) and lower than the targeted $>80 \%$ HIV testing among TB patients as a MDG (WHO, 2004). This could be associated with lack of information about HIV testing and perceived benefit of being tested for HIV and the perception that, TB patients may think that, there is no relationship between TB and HIV.

Respondents who have heard about HCT are less likely to reject HIV testing than their counter parts AOR 0.287(0.084, 0.983), the proportion of respondents who have heard about HCT in the former study is higher $92.96 \%$ Vs $70.2 \%$ compared to study done in southern part of the country (Deribew Abebe et al., 2010) possible reasons could be difference in population being studied, as tuberculosis patients have visited health facilities several times compared to general population. Less than ten $(7 \%)$ of participants in this study didn't know where to get HIV testing, which is probably located in the facility where they are receiving TB treatment, this indicates that TB patients were not sufficiently informed about HIV testing services.

The proportion of tuberculosis patients who were knowledgeable about HIV was low $70 \%$ compared to findings from North Gondar (Ayenew, 2004) and the level of knowledge was high among urban residents compared to rural AOR 2.36(Cl 1.224, 4.549), the same result was also found in China where knowledge and negative attitudes are related to level of education and place of residence i.e urbans are more knowledgeable (Ma Detels et al., 2007), possible reasons could be those in the urban area are more accessible to information easily and the level of education was different among TB patients from urban and rural area the higher the level of education the more likely to be from urban area. 
Table 3: HIV test uptake and related factors among tuberculosis patients on DOTS in East Wollega Zone, Ethiopia, January to February 2011.

\begin{tabular}{|c|c|c|c|}
\hline Variables & Cases $(n=90)$ & Controls (180) & Total (270) \\
\hline \multicolumn{4}{|l|}{ Heard about HCT(VCT,PIHCT) } \\
\hline Yes & $76(84.4 \%)$ & $170(94.4 \%)$ & $251(93 \%)$ \\
\hline No & $14(15.6 \%)$ & $10(5.6 \%)$ & $19(7 \%)$ \\
\hline \multicolumn{4}{|l|}{ Source of information } \\
\hline Health workers/facility & $57(68.67 \%)$ & $135(69.59 \%)$ & $192(69.31 \%)$ \\
\hline Mass media & $10(12.05 \%)$ & $30(15.46 \%)$ & $40(14.44 \%)$ \\
\hline Friends & $8(9.64 \%)$ & $11(5.67 \%)$ & $19(6.86 \%)$ \\
\hline Others & $8(9.64 \%)$ & $18(9.28 \%)$ & $26(9.39 \%)$ \\
\hline \multicolumn{4}{|l|}{ Know where to get HCT } \\
\hline Yes & $83(92.2 \%)$ & $168(93.3 \%)$ & $251(93 \%)$ \\
\hline No & $7(7.8 \%)$ & $12(6.7 \%)$ & $19(7 \%)$ \\
\hline \multicolumn{4}{|l|}{ Pretest counseled } \\
\hline Yes & $80(88.9 \%)$ & $173(96.1 \%)$ & $253(93.7 \%)$ \\
\hline No & $10(11.1 \%)$ & $7(3.9 \%)$ & $17(6.3 \%)$ \\
\hline \multicolumn{4}{|l|}{ Do you agree that HCT is important } \\
\hline Yes & $42(46.7 \%)$ & $168(93.3 \%)$ & $210(77.8 \%)$ \\
\hline No & $48(53.3 \%)$ & $12(6.7 \%)$ & $60(22.2 \%)$ \\
\hline \multicolumn{4}{|l|}{ Is there benefit of being tested for HIV } \\
\hline Yes & $39(43.3 \%)$ & $170(94.4 \%)$ & $209(77.4 \%)$ \\
\hline No & $51(56.7 \%)$ & $10(5.6 \%)$ & $61(22.6 \%)$ \\
\hline \multicolumn{4}{|l|}{$\begin{array}{l}\text { Is it possible in the community to get } \\
\text { confidential testing }\end{array}$} \\
\hline Yes & $64(71.1 \%)$ & $134(74.4 \%)$ & $198(73.3 \%)$ \\
\hline No & $16(28.9 \%)$ & $46(25.6 \%)$ & $62(26.7 \%)$ \\
\hline \multicolumn{4}{|l|}{ Willing to use voluntary HCT in the future } \\
\hline Yes & $4(4.4 \%)$ & $149(82.8 \%)$ & $153(56.7 \%)$ \\
\hline No & $86(95.6 \%)$ & $31(7.2 \%)$ & $117(43.3 \%)$ \\
\hline \multicolumn{4}{|l|}{ Reason for not using HCT } \\
\hline Not sure of confidentiality & $16(18.6 \%)$ & $22(70.96 \%)$ & $38(32.48 \%)$ \\
\hline Afraid of AIDS stigma & $47(54.65 \%)$ & $8(25.8 \%)$ & $55(47.01 \%)$ \\
\hline Don't want to know result \& others & $23(26.74 \%)$ & $1(3.23 \%)$ & $24(20.51 \%)$ \\
\hline \multicolumn{4}{|l|}{ Method preferred to obtain HIV test result } \\
\hline Face to face & $78(86.7 \%)$ & $172(95.6 \%)$ & $250(92.6 \%)$ \\
\hline Telephone & $2(2.2 \%)$ & $1(0.6 \%)$ & $3(1.1 \%)$ \\
\hline Secretive letter & $9(10 \%)$ & $3(1.7 \%)$ & $12(4.4 \%)$ \\
\hline Relative or partner & $1(1.1 \%)$ & $4(2.2 \%)$ & $5(1.9 \%)$ \\
\hline \multicolumn{4}{|l|}{ Health professional preference to offer $\mathrm{HCT}$} \\
\hline Medical doctors & $46(51.1 \%)$ & $78(43.3 \%)$ & $124(45.9 \%)$ \\
\hline Nurses & $29(32.2 \%)$ & $55(30.6 \%)$ & $84(31.1 \%)$ \\
\hline Health officers & $1(1.1 \%)$ & $21(11.7 \%)$ & $22(8.1 \%)$ \\
\hline Any one & $14(15.6 \%)$ & $26(14.4 \%)$ & $40(14.8 \%)$ \\
\hline
\end{tabular}

Higher proportion $(93 \%)$ of respondents knew where to get HCT and $77.4 \%$ of the respondents perceive that there is benefit of being tested for HIV which are both associated with HIV test acceptance, compared to study done in China where only $34.2 \%$ know where to get HCT and $65.6 \%$ perceive that there is benefit of being tested for HIV (Ma Detels et al., 2007), this higher level of knowledge can serve as an entry point for high acceptance rate for HIV testing among TB patients after follow up and continuous intervention, and the use of well trained counselors as suggested by Angotti et al., (2009). Study done in North West Ethiopia also revealed that ever heard of HIV testing and perceived benefit of HIV testing are associated with HIV test acceptance, while a study by Kalichman et al. (2003) shows that individuals who hadn't been tested for HIV were significantly less likely to view beneficial outcome from HIV testing, more likely to perceive adverse testing outcomes and more likely to endorse test avoidance (Kalichman and Simbayi, 2003; Ayenew Leykun et al., 2010). 
Table 4: Joint effect of socio-demographic variables and knowledge, attitude and perceived stigma related to HIV among Tuberculosis patients on DOTS in East Wollega zone, Ethiopia 2011.

\begin{tabular}{|c|c|c|c|c|}
\hline Variables & Cases & Controls & COR(95\%Cl) & AOR(95\%Cl) \\
\hline \multicolumn{5}{|l|}{ Religion } \\
\hline Orthodox & 27 & 69 & 1.00 & 1.00 \\
\hline Muslim & 55 & 53 & $2.067(1.170,3.653)$ & $6.280(2.360,16.710)$ \\
\hline Protestant & 5 & 2 & $0.336(0.120,0.945)$ & $0.453(0.110,1.870)$ \\
\hline Catholic & 3 & 5 & $1.533(0.343,6.864)$ & $7.756(0.693,86.777)$ \\
\hline \multicolumn{5}{|l|}{ Place of residence } \\
\hline Urban & 71 & 116 & $2.062(1.142,3.723)$ & $5.692(1.930,16.783)$ \\
\hline Rural & 19 & 64 & 1.00 & 1.00 \\
\hline \multicolumn{5}{|c|}{$\begin{array}{l}\text { There is benefit of being tested for } \\
\text { HIV }\end{array}$} \\
\hline Yes & 39 & 170 & $0.045(0.021,0.096)$ & $0.085(0.031,0.231)$ \\
\hline No & 51 & 10 & 1.00 & 1.00 \\
\hline \multicolumn{5}{|c|}{$\begin{array}{l}\text { Accept VCT if offered house to } \\
\text { house }\end{array}$} \\
\hline Yes & 16 & 132 & $0.079(0.042,0.148)$ & $0.087(0.035,0215)$ \\
\hline No & 74 & 48 & 1.00 & 1.00 \\
\hline \multicolumn{5}{|c|}{ Satisfaction with current treatment } \\
\hline Good & 52 & 151 & 1.00 & 1.00 \\
\hline Moderate & 26 & 26 & $2.904(1.549,5.443)$ & $4.432(1.571,12.505)$ \\
\hline Poor & 12 & 3 & $11.615(3.154,42.783)$ & $13.193(1.777,97.962)$ \\
\hline \multicolumn{5}{|c|}{ Knowledgeable about HIV } \\
\hline No & 44 & 37 & $3.697(2.135,6.402)$ & $4.709(1.822,12.168)$ \\
\hline Yes & 46 & 143 & 1.00 & 1.00 \\
\hline \multicolumn{5}{|l|}{$\begin{array}{l}\text { Perceived stigma and } \\
\text { discrimination }\end{array}$} \\
\hline Low & 32 & 25 & $3.421(1.870,6.257)$ & $4.889(1.556,15.366)$ \\
\hline High & 58 & 155 & 1.00 & 1.00 \\
\hline
\end{tabular}

Tuberculosis patients those who have received pretest counselling were less AOR 0.324(0.119, 0.881) likely to reject HIV testing compared to those who didn't receive pretest counselling. A study done in Northern part of the country also revealed that up to $76.1 \%$ of missed opportunities can be attributed to service providers and it accounts for loss of $51.7 \%$ HIV diagnosis among these losses, and study by Rodger et al indicates that any patient with TB who are not offered HIV testing is a missed opportunity for testing undiagnosed HIV infected patient (Fetene and Feleke, 2010; Rodger, Story et al., 2010). Its recommended that clients presenting with symptoms or signs of illness possibly attributable to HIV, it is a basic responsibility of health care providers to recommend HIV testing and counselling as part of routine clinical management and as a standard part of health care for everyone attending health facilities in generalized HIV epidemics (FMoH 2007; WHO UNAIDS Unicef Progress Report, 2009).

Complete HIV test uptake (pretest counseled, tested, post test counseled and receive test) was
$96.1 \%$ and its comparable with $96 \%$ VCT acceptance among men from Uganda (Bwambale Sali et al., 2008) and its high compared to findings from other part of the country (Jerene Endale et al., 2007). This could be related with those who have tested for HIV might have low personal risks to be HIV positive and even they may be motivated to accept and receive their test result whatever the test result is. More than half of TB-HIV co-infection $56.5 \%$ have been observed among smear negative pulmonary TB patients, even though there is no significant difference between them this suggests that, individual infected with HIV are not identified early as this study have recruited tuberculosis patients those for whom HIV had not been diagnosed before TB.

A total of $16.3 \%(41 / 251)$ of TB patients(in the source population) are also co-infected with HIV, however its low compared to the findings from other part of the country (Jerene, Endale et al., 2007; Ayenew Leykun et al., 2010) and other African countries (Nuwaha, Kabatesi et al., 2002; Zachariah Teck et al., 2006), but is still high 
compared to the national finding of ANC based surveillance from the area which is $10.4(\mathrm{FMoH}$, 2006) even though there is difference in population studied (pregnant women, routine clients coming for medical treatment compared to TB patients). The prevalence is high among, TB patients from urban $19(16.4 \%)$ area compared to rural $4(6.2 \%)$ and it also decreases as age increase except in the age group 25-34 for whom the prevalence was high, but there is no significant difference for both place of residence and age group which is contrary to findings from Cameroon and Agra India (Hussain Sinha et al., 2006; Njozing Migue et al., 2010). This might be related with low case detection rate in our country while the aforementioned countries have high case detection rates and this could result in small denominator in our country compared to the aforementioned countries.

Tuberculosis patients who rated the treatment given to them as moderate or poor were more likely to reject HIV testing compared to those who rated current treatment given to them as good. This may be related to logistics system in availing anti TB medications earlier as most health centers receive the medications from Woreda/ zonal health bureaus and patients perceived current level of illness and giving less attention to the disease that is not currently found in them.

Of the top reasons claimed for not accepting HIV testing not sure of confidentiality and afraid of AIDS stigma accounts for $32.5 \%$ and $47 \%$ respectively, and this is higher compared to study done in china (Ma Detels et al., 2007). Risky sexual behaviors like having multiple sexual partner will increase once risk of getting AIDS and sex with non-regular partner were found to be associated with rejecting HIV testing, VCT use among men from Uganda and other study from South Africa also shows that clients who are not tested for HIV are engaged in risky sexual behavior including multiple sexual behavior, unprotected sex, never used condom and are injecting drug users (Kalichman and Simbayi, 2003; Bwambale, Ssali et al., 2008). This suggests that TB patients who are engaged in high risk sexual practices might fear about the consequence of post HIV test results, and therefore less likely to undergo HIV testing. Contrary to this study, study done by Siyan et al in Cambodia shows that VCT users had significantly higher HIV risks including more experience of receiving sexually transmitted infections (STI) diagnosis and having genital ulcer (Yi Poudel et al., 2009). Suggesting that there is difference in perceived risks associated with testing for HIV as those who perform risky sexual behavior fear to be tested in the current study while others are eager to know their status associated with their risky behavior.

Tuberculosis patients those who would accept HIV testing if provided house to house are more likely to undergo HIV testing. Other study from Cambodia also shows that TB patients treated at clinics without onsite or nearby HIV testing are less commonly tested for HIV and making HIV testing available to TB patients without the necessity of travelling to a distance HIV testing site is likely to increase HIV testing rates (Kanara, Cain et al., 2009). This study also tries to describe HIV testing in relation to countries health infrastructure system considering the lowest health facility providing HIV testing to be health centers and we have classified presence of HIV testing site as within $10 \mathrm{~km}$ and above $10 \mathrm{~km}$ distance but there is no significant difference among those coming within $10 \mathrm{~km}$ radius and above $10 \mathrm{~km}$ distance to a nearby health institution providing HIV testing AOR $1.178(\mathrm{Cl}$ $0.337,4.118)$.

\section{CONCLUSION}

Among socio-demographic determinants place of residence was found to be associated with HCT uptake. The presence of stigma and discrimination related to HIVIAIDS still remain the main challenge specifically among TB/HIV patients as they are suffering from double burden of disease. The desire to have HIV testing at home is associated with HIV testing. Performing risky sexual behavior like having sex with nonregular partner and infrequent use of condom were associated with HCT acceptability to be low. The likelihood of missing pretests counseling for tuberculosis patient is associated with low utilization of HIV testing. The rate of TB-HIV coinfection is high among TB patients in the study area. The notion of knowledge regarding HIVIAIDS should have to be emphasized and needs due attention as having low knowledge about HIVIAIDS is associated with rejecting HIV testing. Efforts to promote HIV testing utilization require effective strategies to reduce stigmatizing beliefs towards HIV and PLWHA among TB patients. Further research is needed to investigate, TB patients on DOTS among whom HIV have been diagnosed those who have started ART and the need to have HIV testing at optional site like house to house. 


\section{ACKNOWLEDGEMENT}

We would like to thank Addis Ababa University, School of Public Health, for supporting the research Project financially. We gratefully acknowledge participants for their voluntary participation.

\section{REFERENCES}

Abera Bekele., Kate Fleming., Zelalem Habtamu., Andrew Fogarty. (2009). "The association of TB with HIV infection in Oromia Regional National State, Ethiopia in 2006/7." Ethiopian Journal of Health Development 23(1): 63-67.

Aklilu Ayenew Tegegne. (2004). Asessment of willingness of TB patients towards VCT in selected health centers, North Gonder Administrative zone.

Animut Ayenew., Abenet Leykun., Robert Colebunders., Amare Deribew. (2010). Predictors of HIV Testing among Patients with Tuberculosis in North West Ethiopia: A Case-Control Study. PLoS ONE 5(3): 1-5.

Daniel, G. Datiko., Mohammed, A. Yassin., Luelseged, T. Chekol., Lopisso, E. Kabeto., Bernt Lindtjørn. (2008). The rate of TB-HIV co-infection depends on the prevalence of HIV infection in a community. BMC Public Health 8: 266.

Degu Jerene., Aschalew Endale., Bernt Lindtjørn. (2007). Acceptability of HIV counselling and testing among tuberculosis patients in south Ethiopia. BMC International Health and Human Rights 7(4): 1-6.

Federal Democratic Republic of Ethiopia: Population Census Commission. (2008). Summary and statistical report of the 2007 population and Housing census. popualtion size by age and sex. Addis Ababa.

Federal Ministry of Health, Federal HIVIAIDS Prevention and Control Office (2007). Guidelines for HIV Counselling and Testing in Ethiopia.

FMoH (2006). AIDS IN ETHIOPIA.

Francis, M. Bwambale., Sarah, N. Ssali,, Simon, Byaruhanga., Joan, N. Kalyango., Charles, A.S. Karamagi. (2008). Voluntary HIV counselling and testing among men in rural western Uganda: Implications for HIV prevention. BMC Public Health 8(263): 1-12.

Fylkesnes., Knut Siziya., Seter. (2004). A randomized trial on acceptability of voluntary HIV counselling and testing. Tropical Medicine and International Health 9(5): 566-572.

Harriet Mpairwe., Lawrence Muhangi., Stat., Proscovia, B. Namujju., Andrew Kisitu., Alex Tumusiime., Moses Muwanga., James, A.G. Whitworth., Saul Onyang., Benon Biryahwaho. Alison, M. Elliott. (2005). HIV Risk Perception and Prevalence in a Program for Prevention of Mother-to-Child HIV Transmission. Journal of Acquired Immune Deficiency Syndrome 39(3): 354-58.
Hirut, T. Gebrekristos., Mark, N. Lurie., Nkosinathi Mthethwa., Quarraisha Abdool Karim. (2009). Disclosure of HIV status: Experiences of Patients Enrolled in an Integrated TB and HAART Pilot Programme in South Africa. African Journal of AIDS Research 8(1): 1-6.

Ibrahim Sendagire., Imke Schreuder., Mesach Mubiru., Maarten Schim van der Loeff., Frank Cobelens., Joseph Konde-Lule. (2010). Low HIV testing rates among tuberculosis patients in Kampala, Uganda. BMC Public Health 10(1): 177.

Kalichman, S.C., Simbayi, L.C. (2003). HIV testing attitudes, AIDS stigma, and voluntary HIV counselling and testing in a black township in Cape Town, South Africa. Sexually Transmitted Infections 79: $442-447$

Kanara, N. Cain., Chhum, K.P., Eng, V.B., Kim, S. Keo, S. Heller., Varma, J.K. (2009). Association between distance to HIV testing site and uptake of HIV testing for tuberculosis patients in Cambodia. International Journal of Tuberculosis and Lung Disease 13(2): 226-31.

Keertan Dheda., Karen Shean., Alimuddin Zumla., Motasim Badri., Elizabeth M. Streicher., Liesl PageShipp., Paul Willcox., Melanie-Anne John., Gary Reubenson., Darshini Govindasamy., Michelle Wong., Xavier Padanilam., Alicia Dziwiecki., Paul, D. van Helden., Sweetness Siwendu., Julie Jarand., Colin, N. Menezes., Avril Burns., Thomas Victor., Robin Warren., Martin, P. Grobusch., Martie van der Walt., Charlotte Kvasnovsky. (2010). Early treatment outcomes and HIV status of patients with extensively drug-resistant tuberculosis in South Africa: a retrospective cohort study. Lancet 375: 1798-807.

Kifle Woldemichael., Fetene Deribie., Mesele Bezabih., Abraham Aseffa., Robert Colebunders. (2010). Prejudice and misconceptions about tuberculosis and HIV in rural and urban communities in Ethiopia: a challenge for the TB/HIV control program. BMC Public Health 10.

Knut Fylkesnes., Seter Siziya. (2004). A randomized trial on acceptability of voluntary HIV counselling and testing. Tropical Health and International Medicine 9(5): 566-572.

Kouyoumdjian., Fiona, G. Seisay., Alhassan, L. Kargbo., Brima Khan., Sheik, H. (2010). The voluntary HIV counselling and testing service in Kenema District, Sierra Leone, 2004-2006: a descriptive study. BMC International Health and Human Rights 10(14): 1-8.

Maria, A. Pando., Cristina De Salvo., Christian, T. Bautista., Lindsay Eyzaguirre., Gladys Carrion., Miguel Feola., Isabel Lado., Marta Hoffman., Mirna, M. Biglione., Jean, K. Carr., Silvia, M. Montano., Jose, L. Sanchez., Mercedes Weissenbacher., Maria, M. Avil.a (2008). Human immunodeficiency virus and tuberculosis in Argentina: prevalence, genotypes and risk factors. Journal of Medical Microbiology 57: 190-197. 
Gebi \& Alemayehu

Netsanet, W. Fetene., Amsalu, D. Feleke. (2010). Missed Opportunities for earlier HIV testing and diagnosis at the health facilities of Dessie town, North East Ethiopia. BMC Public Health 10: 1-5.

Nicole Angotti., Agatha Bula., Lauren Gaydosh., Eitan Zeev Kimchi., Rebecca, L. Thornton., Sara, E. Yeatman. (2009). Increasing the acceptability of HIV counseling and testing with three C's: Convenience, confidentiality and credibility. Social Science \& Medicine 68: 2263-2270.

Nuwaha, F. Kabatesi., Muganwa, M., Whalen, C.C. (2002). Factors Influencing Acceptability Of Voluntary Counselling And Testing For Hiv In Bushenyi District Of Uganda. East African Medical Journal 79(12): 626-632.

Nwarbébé Barnabas Njozing., San Sebastian Miguel., Pius Muffih Tih., Anna-Karin Hurtig. (2010). Assessing the accessibility of HIV care packages among tuberculosis patients in the Northwest Region, Cameroon. BMC Public Health 10:129.

Rodger, A.J., Story, A., Fox, Z., Hayward, A. (2010). HIV prevalence and testing practices among tuberculosis cases in London: a missed opportunity for HIV diagnosis?" Thorax 65: 63-69.

Salvatore Pignatelli., Jacques Simpore., Virginio Pietra., Laurent Ouedraogo., Ghislaine Conombo., Nuccia Saleri., Cecilia Pizzocolo., Giuseppina De laco., Francois Tall., Adama Ouiminga., Giampiero Carosi., Francesco Castelli. (2006). Factors predicting uptake of voluntary counselling and testing in a real-life setting in a mother-and-child center in Ouagadougou, Burkina Faso. Tropical Health and International Medicine II(3): 350-357.

Sarker, M., Sanou, A., Snow, R., Ganame, J., Gondos, A. (2007). Determinants of HIV counselling and testing participation in a Prevention of Mother-toChild Transmission programme in rural Burkina Faso. Tropical Medicine and International Health 12 (12): 1475-1483.

Sophia Vijay., Soumya Swaminathan., Preetish Vaidyanathan., Aleyamma Thomas, L. S., Chauhan, Prahlad Kumar, Sonali Chiddarwar, Beena Thomas., Puneet, K. Dewan. (2009). "Feasibility of ProviderInitiated HIV Testing and Counselling of Tuberculosis Patients Under the TB Control Programme in Two Districts of South India." PLoS ONE 4(1): 1-7.

Srikantiah, P. Lin., Walusimbi, M. Okwera., Luzze, H. Whalen., Boom, W.H. Havlir., Charlebois, E.D. (2007). Elevated HIV seroprevalence and risk behavior among Ugandan TB suspects: implications for HIV testing and prevention. International Journal of Tuberculosis and Lung Disease 11(2): 168-74.

Tahziba Hussaina., Shikha Sinhaa., Kulshreshthaa, K.K., Yadava, V.S., Pradeep Sharmab., Senguptaa, U., Katoch, V.M. (2006). Seroprevalence of HIV infection among tuberculosis patients in Agra, India-a hospital-based study. Tuberculosis 86: 5459.
Sci. Technol. Arts Res. J., April-June 2012, 1(2):31-42

Wei Ma., Roger Detels., Yuji Feng., Zunyou Wu., Limei Shen., Yu Li., Zezhen Li., Fang Chen., Aimin Wang., Taiming Liu. (2007). Acceptance of and barriers to voluntary HIV counselling and testing among adults in Guizhou province, China. AIDS 21 (suppl 8): S129-S135.

WHO. (2004). Guidelines for HIV Surveillance Among Tuberculosis Patients.

WHO UNAIDS Unicef (Progress Report 2009). TOWARDS UNIVERSAL ACCESS: Scaling up priority HIVIAIDS interventions in the health sector.

Yi, S., Poudel, K. C., Yasuoka, J., Ichikawa, M., Tan, V., Jimba, M. (2009). Influencing factors for seeking HIV voluntary counseling and testing among tuberculosis patients in Cambodia. AIDS Care 21(4): 529-534.

Zachariah, R., Spielmann, M. P., Harries, A. D., Salaniponi, F. L. (2003). Voluntary counselling, HIV testing and sexual behaviour among patients with tuberculosis in a rural district of Malawi. International Journal of Tuberculosis and Lung Disease 7(1): 6571.

Zachariaha, R., Teckb, R., Buhendwab, L., Labanab, S., Chinji, C., Humbleta, P., Harries, A.D. (2006). How can the community contribute in the fight against HIVIAIDS and tuberculosis? An example from a rural district in Malawi. Transactions of the Royal Society of Tropical Medicine and Hygiene 100: 167-175. 